\title{
Challenges in the surgical management of spine trauma in the morbidly obese patient: a case series
}

\author{
Clinical article
}

\author{
Hannah E. Rosenfeld, ${ }^{1}$ Rebecca Limb, B.M.B.S., ${ }^{2}$ Patrick Chan, M.D., ${ }^{2}$ \\ Mark Fitzgerald, M.B.B.S., ${ }^{3}$ William Pierre Litherland Bradley, M.B.Ch.B., ${ }^{4,5}$ \\ AND JeFFrey V. RosenfeLd, M.D., M.S. ${ }^{2,5}$
}

${ }^{1}$ Medical Faculty, University of Adelaide; ${ }^{2}$ Department of Neurosurgery, and ${ }^{3}$ Trauma Service, The Alfred Hospital, Melbourne; ${ }^{4}$ Department of Anaesthesia, The Alfred Hospital and Monash University, Melbourne; and ${ }^{5}$ Department of Surgery, Monash University, Melbourne, Australia

\begin{abstract}
Object. The treatment of morbidly obese individuals with spine trauma presents unique challenges to spine surgeons and trauma staff. This study aims to increase awareness of current limitations in the surgical management of spine trauma in morbidly obese individuals, and to illustrate practical solutions.

Methods. Six morbidly obese patients were treated surgically for spine trauma over a 2-year period at a single trauma center in Australia. All patients were involved in high-speed motor vehicle accidents and had multisystem injuries. All weighed in excess of 265 pounds $(120 \mathrm{~kg}$ ) with a body mass index $\geq 40$ (range 47.8-67.1). Cases were selected according to the considerable challenges they presented in all aspects of their management.

Results. Best medical and surgical care may be compromised and outcome adversely affected in morbidly obese patients with spine trauma. The time taken to perform all aspects of care is usually extended, often by many hours. Customized orthotics may be required. Imaging quality is often compromised and patients may not fit into scanners. Surgical challenges include patient positioning, surgical access, confirmation of the anatomical level, and obtaining adequate instrument length. Postoperative nursing care, wound healing, and venous thromboembolism prophylaxis are also significant issues.

Conclusions. Management pathways and hospital guidelines should be developed to optimize the treatment of morbidly obese patients, but innovative solutions may be required for individual cases. (http://thejns.org/doi/abs/10.3171/2013.4.SPINE12876)
\end{abstract}

\section{Key Words • spine trauma $\quad$ morbid obesity $\bullet \quad$ anesthesia}

$\mathrm{T}$ HE prevalence of obesity is increasing both in Australia and in other Western countries, reaching "pandemic" proportions. 19,40,44 The worldwide prevalence of obesity almost doubled between 1980 and 2008 , from $4.8 \%$ to $9.8 \%$ in men and from $7.9 \%$ to $13.8 \%$ in women. ${ }^{19}$ Australian men and women have a mean BMI that is among the highest in the world. ${ }^{19} \mathrm{~A}$ population study in 2000 showed that the prevalence of overweight individuals and obesity in Australia is greater than the worldwide mean, with $39.0 \%$ of Australians overweight and $20.8 \%$ obese. $^{8}$

Obesity is generally defined in terms of the BMI

\footnotetext{
Abbreviations used in this paper: ASIA = American Spinal Injury Association; $\mathrm{BMI}=$ body mass index; $\mathrm{LMWH}=$ low-molecularweight heparin.
}

as measured by weight in kilograms divided by height in meters squared ${ }^{49}$ According to the definitions of the WHO, a BMI of 18-24.99 is normal, 25-29.99 is overweight, 30-39.99 is obese, and $\geq 40$ is morbidly obese. ${ }^{49}$ In addition to the well-recognized medical, social, and economical consequences, this increasing level of obesity poses significant challenges for health care professionals in the multitrauma setting.

We have encountered unique problems in our trauma center regarding the surgical management of spine trauma in the morbidly obese patient. This paper aims to highlight these problems using an illustrative case series. We will propose solutions using the experience gained from our caseload, to contribute to a growing body of knowledge on this topic that will be of interest to spine surgeons worldwide. 


\section{Methods}

Cases were identified by retrospectively reviewing operative lists of surgically treated spine trauma patients in the preceding 2 years at the Alfred Hospital, a Level I trauma center. Patients with spine trauma treated surgically and classified as morbidly obese with particular difficulties in perioperative management were selected and the online imaging, operative reports, and anesthetic documentation analyzed. A low-risk ethics application to conduct the study was approved by the Alfred Hospital Ethics Committee.

\section{Results}

Six morbidly obese patients treated surgically for traumatic spinal injuries between January 2010 and January 2012 were identified. All patients weighed in excess of $120 \mathrm{~kg}(265 \mathrm{lbs})$, and had a BMI $>40$. All were involved in high-speed motor vehicle accidents and suffered multisystem injuries. In all but 1 of the cases (Case 2 ), the only diagnostic imaging modality available preoperatively was CT because these patients were unable to fit into our hospital MRI machines due to their body habitus. A wide variety of unique challenges and unanticipated difficulties were encountered, which required solutions individually tailored to each patient.

\section{Case 1: Unstable Displaced Type III Dens Fracture With Significant Distraction and Posterior Ligamentous Disruption}

This 38-year-old woman, with a weight of $140 \mathrm{~kg}$ (309 lbs), height of $171 \mathrm{~cm}$ (67.3 inches), and BMI of 47.8, was the driver of a car involved in a high-speed headon collision. She was conscious and neurologically fully intact in all 4 limbs. She sustained an unstable Type III dens fracture of C-2 with posterior ligamentous disruption, significant displacement, and angulation of the fracture (Fig. 1A and B). This was an unstable injury that required reduction and fixation. The initial stabilization required a customized handmade halo-thoracic vest. After applying the customized halo-thoracic vest, it took the next 12 hours to attempt to achieve a closed reduction.

Due to the patient's body habitus, the plain radiograph of the cervical spine obtained after application of the brace failed to provide adequate views of the dens to determine the reduction of fracture (Fig. 1C). Repeat CT demonstrated persistent, unacceptable displacement of the C-2 fracture. Closed reduction of the cervical spine was difficult to perform using standard fluoroscopic guidance because of the poor $\mathrm{x}$-ray penetrance. Confirmation of fracture reduction required further CT. Unfortunately, due to difficulties caused by the patient's body habitus, attempts at closed reduction of the C-2 fracture were unsuccessful. Open reduction and internal fixation were therefore indicated.

The patient underwent $\mathrm{C} 1-2$ posterior fusion via the Harms technique (Fig. 1D). Positioning the patient prone added approximately 1.5 hours to the operation and required 8 people to facilitate. Intraoperatively, the patient was prone on a Gillespie pillow, a flat plastic cushion placed on the operating table that has a hollow center for the chest and abdomen (Hipac Goulburn). During the operation, while the patient was on this pillow with her head fixated in a Halo ring attached to the Mayfield clamp, a large circuit leak was suddenly detected. The endotracheal tube had become dislodged, resulting in the tube tip being located in the back of the oropharynx in a fully anesthetized and paralyzed prone patient.

The anesthesia team rapidly repositioned the endotracheal tube using a fiberscope without any desaturation, while the patient remained prone. If this repositioning had been unsuccessful, the patient would have been returned to the supine position to facilitate reintubation, with or without the use of a supraglottic device to maintain oxygenation. This action would have required removing all drapes and surgical equipment, rapid closure of the wound, a significant number of people to turn the patient supine in a controlled fashion, and ideally would have meant replacing the remainder of the halo-thoracic brace first. This procedure could have resulted in a significant, sustained period of hypoxia if oxygenation could not have been maintained, with likely hypoxic injury to the brain and/or spinal cord.

The postoperative course was complicated by a cervical wound breakdown and infection, compounded by the wound traversing a large skin crease. This wound was successfully managed nonoperatively using long-term intravenous antibiotics and specialist wound care. Pressure area care was extremely difficult to manage.

The patient was followed up 3 months postoperatively. She had recovered well without neurological deficit and her cervical wound had healed well. The cervical spine was in alignment, with stability noted on flexion and extension radiographs.

\section{Case 2: Compression Burst Fracture at C-4}

This 18-year-old female patient was transferred from a rural interstate location $(445 \mathrm{~km}$ from the trauma center), after a high-speed motor vehicle accident. Her weight was $125 \mathrm{~kg}$ (276 lbs), height $161 \mathrm{~cm}$ (63.3 inches), and BMI 48.2. Ambulance crews reported her to be tetraplegic at the scene, with a sensory level at C-4. The initial diagnosis was a suspected C-4 complete spinal cord injury (ASIA Grade A). She underwent intubation and mechanical ventilation for transfer to the trauma center.

Computed tomography scans and MRI showed a C-4 burst fracture with subluxation and retropulsion of $\mathrm{C}-4$ causing spinal cord compression (Fig. 2A-C); other injuries included pulmonary and cardiac contusions. The patient underwent an emergency open reduction, C-4 corpectomy, and internal fixation and anterior fusion from C-3 to C-5 using an iliac strut graft and cervical locking plate (Fig. 2D). The technical difficulties included achieving and maintaining surgical retraction for both neck and right iliac exposure, which necessitated a longer incision and longer retractor and instruments.

There was an initial significant delay in transferring the patient from the interstate hospital due to weight restrictions of the air transport. The time of injury was 0300 (3:00 in the morning) but the patient did not arrive at the trauma center by road ambulance until 2140 (9:40 at night), which entailed an 18-hour delay. Postoperative ventilation 
Managing spine trauma in the morbidly obese

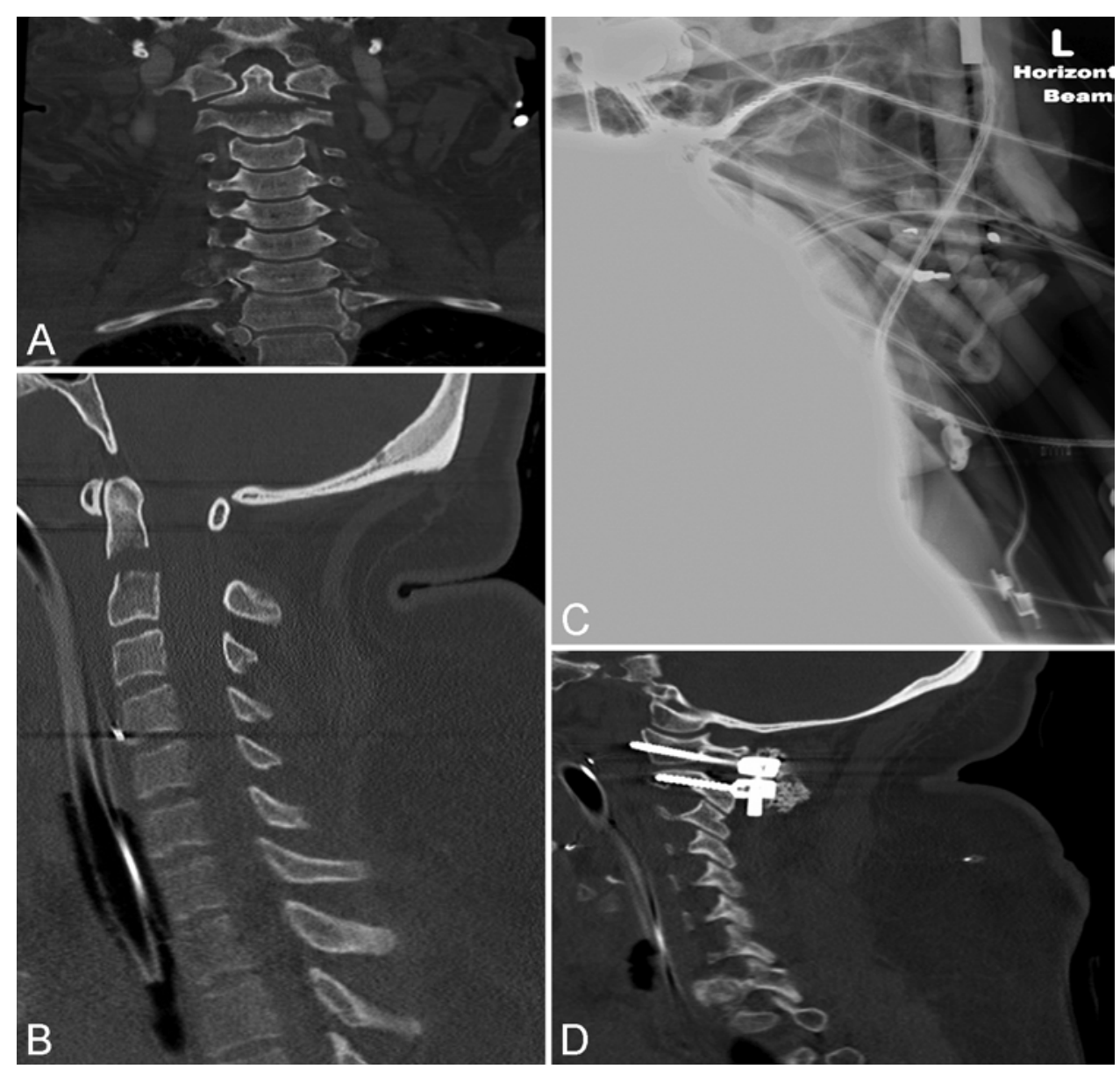

FIG. 1. Case 1. A: Coronal CT scan showing a Type III dens fracture of C-2 with significant vertical displacement. B: Sagittal CT scan showing vertical distraction and angulation of the dens and widening of the posterior elements of $\mathrm{C} 1-2$, indicating gross ligamentous disruption and fracture instability. C: Lateral radiograph of the patient's cervical spine showing the extreme limitation of the plain radiographs in this patient. D: Sagittal CT scan showing C1-2 posterior fusion (the Harms technique).

problems in the intensive care unit were encountered, with high ventilatory pressures required and persistent hypoxia due to a combination of lower lobe collapse and mucus plugging. A tracheostomy was performed. The alignment

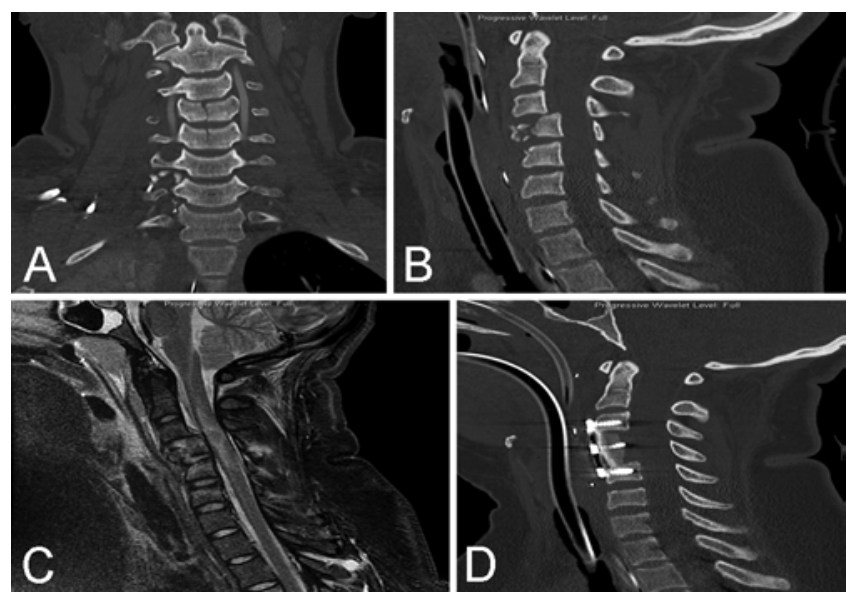

Fig. 2. Case 2. A-C: Coronal (A) and sagittal (B) CT scans and sagittal MR image (C) demonstrating compression fractures of $C-4$ and C-5. D: Postoperative sagittal CT scan demonstrating the C3-5 anterior fusion. of the spine on plain radiographs was satisfactory. The patient was transferred to a specialist spinal rehabilitation unit. There was no recovery of neurological function in the upper or lower limbs at this stage, and the patient required ongoing assisted ventilation.

At last review 29 months after the injury, she remained a C-4 complete quadriplegic (ASIA Grade A) requiring continuous positive airway pressure for respiratory support, a suprapubic catheter, and baclofen $60 \mathrm{mg}$ per day for limb spasticity. She suffered autonomic dysreflexia, but there was no neuropathic pain. She was living in a home environment with her parents but required 24-hour care. There was bone fusion present on follow-up dynamic radiography.

\section{Case 3: Fracture of T11-12 With Traumatic Disc Disruption, and Hyperextension Deformity}

This 56-year-old woman was involved in a motor vehicle accident at $90-100 \mathrm{~km} / \mathrm{hr}(56-62 \mathrm{mph})$. Her weight was $175 \mathrm{~kg}$ (386 lbs), height $161.5 \mathrm{~cm}$ (63.5 inches) and BMI 67.1. She was neurologically fully intact on assessment. A CT scan demonstrated hyperextension injury at T11-12, with fracture of the T-11 and T-12 endplates, and significant anterior widening of the disc space (Fig. 3 
left). The patient underwent an open reduction and T9-L1 posterior fusion (Fig. 3 right).

Positioning the patient intraoperatively was a significant challenge. Our normal practice for thoracic spine fractures is to position the patient prone on a Gillespie pillow or, less commonly, a Wilson frame (Mizuho OSI). Due to the size of the patient, a Doig frame (Denyers International) was selected. However, significant pressure areas and ventilation issues were identified where the patient's abdomen protruded through the frame. This situation was believed to present an unacceptably high risk of skin breakdown and respiratory compromise. Therefore the patient was turned back supine on the bed prior to being repositioned prone on a Jackson table (Mizuho OSI). The whole process involved approximately 10 members of the staff and delayed the start of the operation by an estimated 2.5 hours.

Postoperatively, the patient's extreme morbid obesity meant nursing care was problematic. In particular, nursing staff were unable to turn or lay the patient on her side, even with multiple personnel present, resulting in a sacral pressure wound that developed quickly and areas of skin breakdown under the breasts. On discharge to rehabilitation, the patient was unable to mobilize due to lower-limb orthopedic injuries, but a clinical review at 3 months revealed intact motor and sensory function in the lower limbs.

The last follow-up evaluation occurred 3 months postoperatively. There was no neurological deficit in the lower limbs and no significant issues with pain. She was independently mobilizing without aids. A CT scan of the thoracolumbar spine showed that alignment was maintained but there was early bone union.

\section{Case 4: Bilateral Facet Fractures at C7-T1, Traumatic Anterolisthesis of $C-7$ on $T-1$}

This 53-year-old man, weighing $186 \mathrm{~kg}$ (410 lbs), with a height of $188 \mathrm{~cm}$ (74 inches) and a BMI of 52.6, was thrown 3-4 meters from a motorbike while moving at high speed. He arrived at the trauma center neurologically fully intact in all 4 limbs, although complaining of neck and upper thoracic pain. A CT scan demonstrated right C7-T1 facet and left C-7 lamina fractures with traumatic anterolisthesis of C-7 on T-1 (Fig. 4A).

Paramedics were unable to fit the patient with a rigid collar due to the large dimensions of the patient's neck. He was immobilized using sandbags and head taping to a
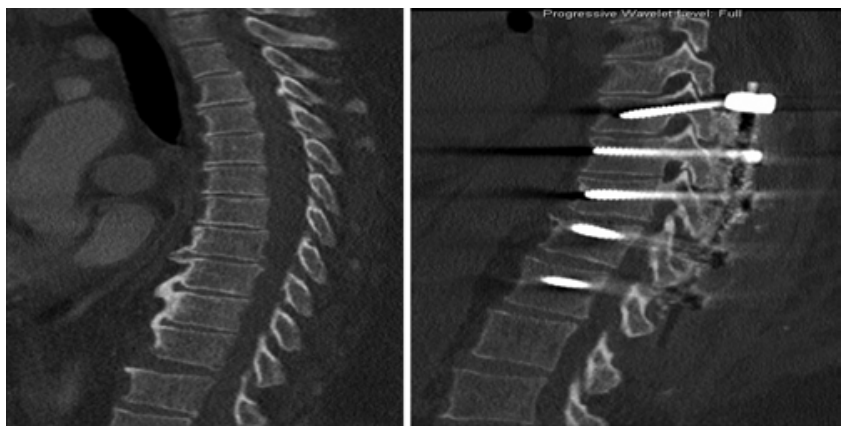

FIG. 3. Case 3. Left: Sagittal CT scan showing a hyperextension injury through the T11-12 disc space. Right: Sagittal CT scan demonstrating posterior open reduction and fusion from T-9 to L-1.

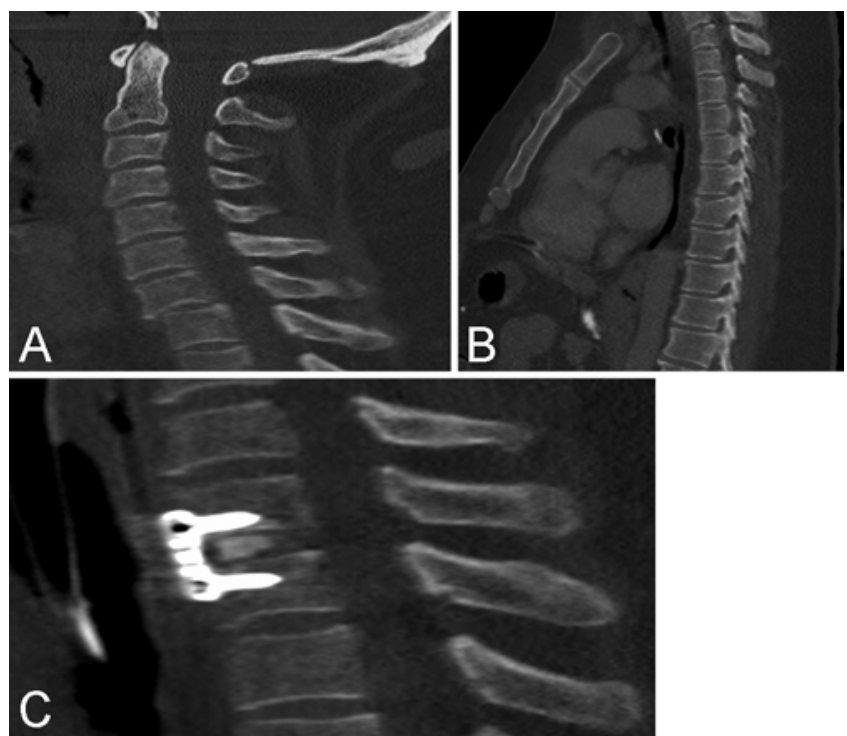

FIG. 4. Case 4. A: Sagittal CT scan showing C7-T1 traumatic anterolisthesis and C-7 and T-1 facet fractures. B: Sagittal chest CT scan showing the level of injury in relation to the sternal manubrium. C: Sagittal CT scan demonstrating anterior cervical discectomy and fusion from C-7 to T-1 following sternotomy.

wider spinal board for transfer. Upon arrival to our trauma center, immobilization of the cervical spine remained a significant challenge. He was eventually fitted with a low-temperature thermoplastic material, which was custom-molded into a semirigid collar by our orthotist, but its extent of immobilization remained suboptimal.

The unstable C7-T1 fracture-subluxation required reduction and fixation. Due to the patient's body habitus and very short neck, difficulty in performing ventilation and positioning him prone, and given that he required internal plate fixation of his flail chest, we elected to perform the open reduction and internal fixation of the C7T1 fracture-subluxation through a median sternotomy, as an extension of the surgery for his flail chest, performed by a cardiothoracic surgeon (Fig. 4B). In addition, intraoperative localization with the image intensifier was impossible due to the patient's short neck and large shoulders, despite traction on the arms. A spinal needle was therefore inserted in the C3-4 disc space, confirmed with the image intensifier, and the needle marker was then used to count down to the disc space of C7-T1 (Fig. 4C).

Postoperatively, in the intensive care unit, the patient's size and severe obstructive sleep apnea complicated the extubation and a surgical tracheostomy was required to safely overcome these respiratory issues.

At the 3- and 12-month postoperative reviews, the patient had a right vocal cord paresis causing dysphonia, likely due to a recurrent laryngeal nerve palsy. He did not have neurological deficit in his limbs and he was mobilizing well. The vocal cord paresis continued. A CT scan showed satisfactory alignment with bone fusion.

\section{Case 5: Pedicle and Facet Fractures With Subluxation at} C5-6 and C6-7, and T-2 and T-3 Compression Fractures

This 48-year-old woman was admitted following a high-speed motor vehicle accident. Her weight was 162 
$\mathrm{kg}$ (357 lbs), height $166 \mathrm{~cm}$ (65 inches), and BMI 58.8. On examination there was a tetraparesis affecting myotomes C6-8 bilaterally ( $2 / 5$ motor grade power) and both lower limbs (1/5 on the right, $3 / 5$ on the left). There was no sensory deficit or sensory level. This injury was classified as an incomplete spinal cord injury (ASIA Grade C).

Magnetic resonance imaging to assess for any element of disc prolapse prior to reduction of the deformity was not possible due to the patient's dimensions. In addition, diagnostic CT scans were significantly degraded by the patient's size. The injuries identified were bilateral pedicle and facet fractures with subluxation at C5-6 and C6-7, and additional compression fractures at T-2 and T-3 (Fig. 5 upper).

The patient underwent an emergency 2-level anterior cervical discectomy and fusion (C5-6 and C6-7). The intraoperative image intensifier was only able to penetrate the C-1 and C-2 levels, with the view of her subaxial cervical spine obstructed by her shoulders and adipose tissues. Intraoperative counting of the spinal level was not possible due to limited anterior exposure, due to both her adipose tissue and anatomy, as well as the length of retractors. Therefore, a single 3.5-mm cervical plate fixation screw was inserted into the accessible vertebral body, the wound was temporarily closed, and repeat CT performed (Fig. 5 lower). This scan revealed the screw to be in the vertebral body of C-5. Other levels were able to be identified correctly once the patient was brought back to the operating room and the operation recommenced. The associated delays and transfers could have placed the patient at increased risk of infection and neurological damage. The duration of the entire procedure was 7 hours. On discharge to rehabilitation, the patient had a residual right hemiparesis of $3 / 5$ motor grade power and was unable to mobilize independently.

At the 2-month postoperative review, her tetraparesis had almost completely resolved (ASIA Grade D) but she complained of neuropathic paresthesia in her lower limbs. At 1 year postoperatively the painful paresthesia in her lower limbs had resolved and there was no neurological deficit (ASIA Grade E). The 1-year follow-up CT scan showed satisfactory bone union and alignment.

\section{Case 6: Fracture Dislocation at T-5 With Spinal Cord Transection}

This 69-year-old woman, weighing $140 \mathrm{~kg}$ (309 lbs), with a height of $160 \mathrm{~cm}$ (62 inches) and a BMI of 54.7, was the driver of a car that was rear-ended at high speed. On admission to the trauma center, she was noted to be paraplegic with no anal tone and a sensory level in the midthoracic region. The preliminary diagnosis was a complete spinal cord injury (ASIA Grade A). Other significant injuries included bilateral tension pneumothoraces and hemothoraces with significant hemodynamic instability. The patient was intubated and stabilized with bilateral tube thoracostomies. Subsequent CT scans confirmed a T-5 vertebral body fracture with significant posterior dislocation, appearing to totally transect the spinal cord at this level (Fig. 6 upper). She was transferred to the operating room where she underwent open reduction and posterior fusion from T-2 to T-9 (Fig. 6 lower).
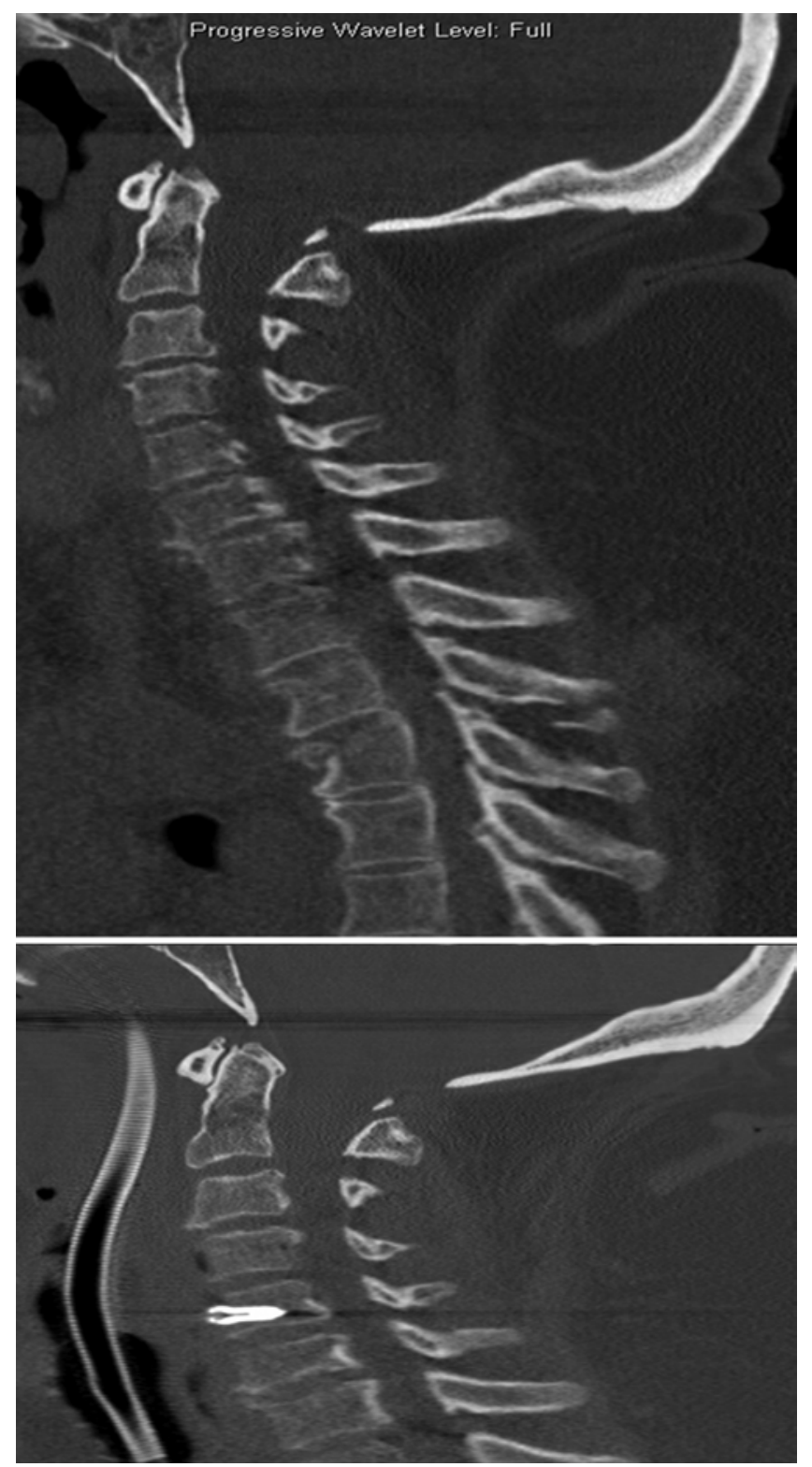

FIG. 5. Case 5. Upper: Sagittal CT scan (quality degraded) demonstrating the cervical and upper thoracic spine injuries. Lower: Sagittal CT scan demonstrating intraoperative screw placement in the vertebral body of $\mathrm{C}-5$.

Intraoperatively, a decompressive laminectomy was performed at the level of the injury where severe damage and transection of the spinal cord was confirmed. Following decompression and during insertion of the thoracic pedicle screws, the patient became severely hypotensive. Intravenous fluid resuscitation was commenced until the anesthesia team discovered that the intravenous cannula in the right forearm was displaced with extensive extravasation into the surrounding tissues. The operation was swiftly completed. An immediate consultation with plastic surgery resulted in a diagnosis of compartment syndrome of the right forearm. The patient was subsequently taken for forearm fasciotomies, and later secondary closure of the wound under the care of the plastic surgery team.

Postoperatively, she developed the complication of bilateral lower-limb deep venous thrombosis and began 

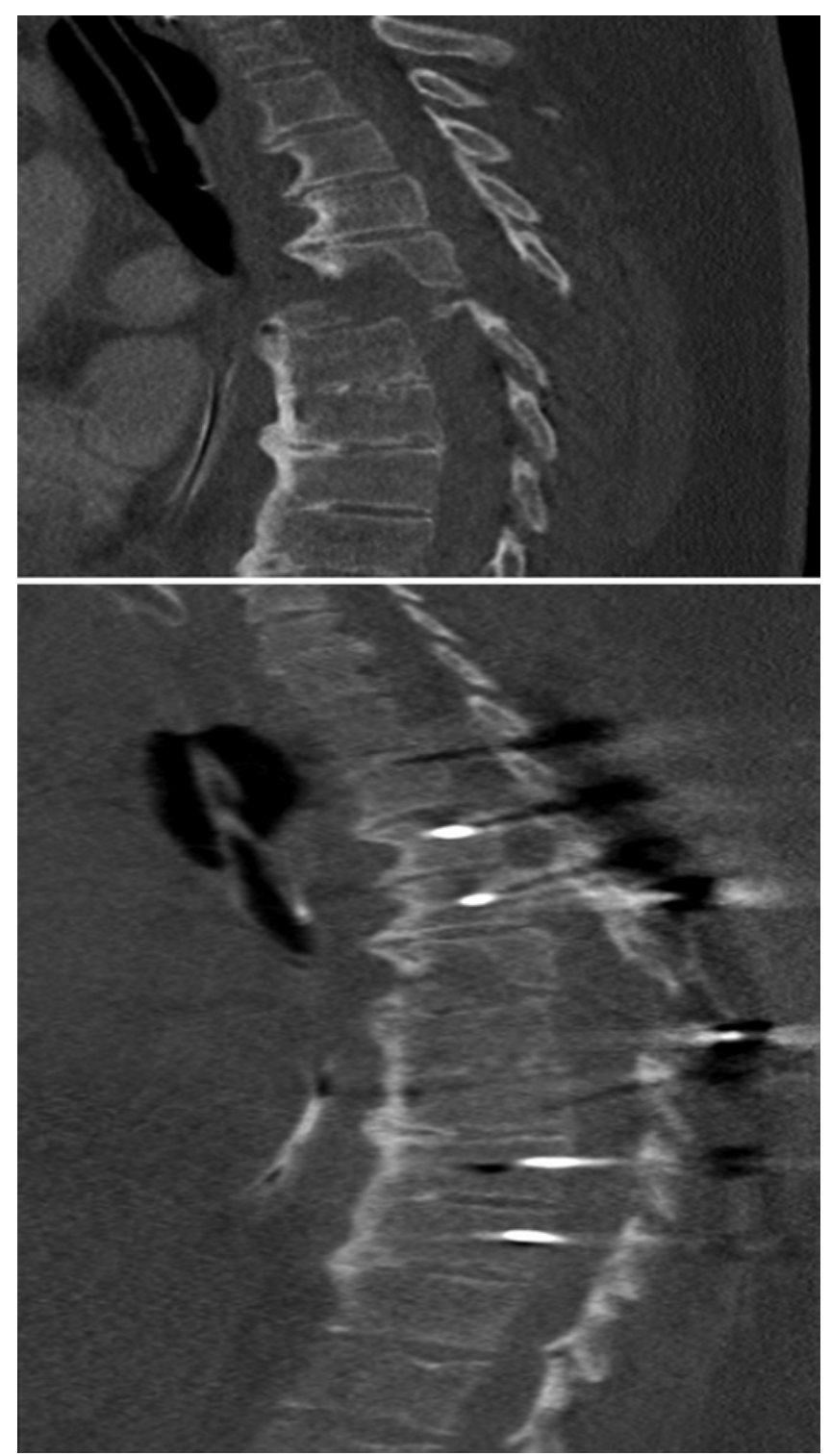

FIG. 6. Case 6. Upper: Sagittal CT scan showing the fracture dislocation at T-5 after the patient was rear-ended in a high-speed motor vehicle accident. Lower: Postoperative sagittal CT scan demonstrating reduction and fixation of the fracture dislocation at T-5.

receiving warfarin. The patient did not regain lower-limb sensory or motor function, and was transferred to the regional spinal rehabilitation unit.

The last follow-up evaluation occurred 7 months postoperatively upon discharge from the spinal rehabilitation unit. Her neurological level remained T-5 (ASIA Grade A). She suffered from neuropathic pain in her lower limbs, which was treated with pregabalin. Radiologically there was satisfactory spinal alignment and instrumentation on radiographs. She was confined to a wheelchair and was transferred to residential care.

\section{Discussion}

The management of acute spine injury in the morbidly obese patient raises many challenges for the trauma team. These issues may compromise best medical and surgical practice and adversely affect patient outcomes. Data regarding morbidity and mortality in the morbidly obese trauma patient are inconsistent, with some studies showing no increase in perioperative mortality and others showing a strong correlation between BMI and mortality. 7,11,14,16,17,26,32-34,50

Challenges in areas such as prehospital care and transport, radiology, anesthesia, surgical technique and instrumentation, postoperative complications, and orthotics were encountered in the cases described above. With the escalating prevalence of obesity in Western countries, management challenges such as these will be encountered with growing frequency. We have categorized these challenges and presented them for discussion in the order they are usually faced by the trauma, anesthesia, and spine surgery teams.

\section{Transport and Transfer}

Significant logistical problems are posed by the weight of bariatric patients. Transferring a patient from the scene of a trauma necessitates special equipment and expertise, which is not often available in remote locations. This problem has particular significance due to the long distances between rural locations and tertiary trauma centers in Australia with a reliance on air ambulance transfer. Rotary and fixed-wing aircraft are weight limited, with cabin size constraints often necessitating that patients be transferred long distances by road. These factors delay the arrival of bariatric patients to a trauma center with delayed definitive diagnoses and management of life-threatening injuries. Delays may have significant implications for the neurological outcomes of patients with spinal cord and spinal column injuries.

\section{Anesthesia and Resuscitation}

Perioperative care of the morbidly obese patient presents unique challenges for the anesthesia team. Intubation is often a significant challenge in the morbidly obese due to poor visibility of the soft palate, tonsils, and uvula upon mouth opening. ${ }^{1,5,9,13,22,29}$ Short necks with indistinct anatomical landmarks and the inability to hyperextend the patient's neck due to associated spinal injuries increases the technical difficulty of insertion of a surgical airway as a salvage technique in cases of unsuccessful intubation and ventilation.

Facial anatomy may impede the anesthesiologist's ability to adequately bag-mask the patient. Restrictive tidal volumes in the supine position may be associated with inadequate preoxygenation and associated rapid desaturation following the induction of general anesthesia. Subsequent mechanical ventilation is also difficult due to the restrictive chest wall and altered pulmonary mechanics noted in the obese..$^{9,22,38}$ This difficulty is exacerbated when the patient is placed prone for posterior spinal approaches. This was a major concern in Case 4, in a patient with a weight of $186 \mathrm{~kg}$ and flail chest requiring surgical fixation; it also would have been very difficult to turn this patient prone because of occupational health and safety issues for the staff. This challenge contributed to the decision to use the anterior approach. 
Endotracheal tubes are more easily dislodged in the morbidly obese, as in Case 1, and require careful securing of the tube. There should always be direct communication between the anesthesiology and surgical teams when spinal manipulation involving the airway occurs.

Excess subcutaneous tissue renders intravenous access difficult. ${ }^{13,24,28}$ As in Case 6, the risk of dislodgement or misplacement of peripheral intravenous cannulae in the morbidly obese may be difficult to identify and significantly compromise the patient's condition. Urinary bladder catheterization and arterial line placement are similarly technically difficult in the morbidly obese.

Monitoring is less accurate in the morbidly obese: ${ }^{5}$ electrocardiography traces, noninvasive blood pressure monitoring, and pulse oximeters may be inaccurate in this patient population, ,,13,22 and there should be a low threshold for invasive monitoring in these patients. ${ }^{5,13}$

Postoperatively, obese patients with obstructive sleep apnea, who have undergone a procedure while prone, are more susceptible to developing airway edema and obstruction. ${ }^{30}$ A planned extubation is performed in the intensive care unit with the patient awake and able to respond to commands. Immediate postoperative continuous positive airway pressure and early chest physiotherapy are recommended. ${ }^{13,30,38}$ There may be a greater indication for surgical tracheostomy in these patients.

\section{Imaging}

Preoperative imaging with all modalities is more difficult and less accurate in the obese. Plain radiographs are of lower quality due to poor x-ray penetration through excessive adipose tissue and increased scatter. ${ }^{12,47}$ The use of CT and MRI is also limited by excess adiposity in the morbidly obese. Computed tomography scans are often degraded, resulting in lower diagnostic capabilities and greater radiation exposure. ${ }^{12,41,46}$ Magnetic resonance machines have weight and girth restrictions, often making them unusable in this patient group; the open MRI machine may provide a solution to this problem..$^{12,41}$

\section{Surgical Positioning}

Standard operating tables can withstand patient weights of approximately $150 \mathrm{~kg}^{5}$ An operating table specially designed for obese patients may be necessary for patients who exceed the weight limit. ${ }^{5}$ If such a table is not available, 2 standard operating tables can be clamped together., ${ }^{1,42}$

Patient transfers and positioning are challenging, time consuming, and potentially hazardous to staff. Additional specially trained operating room personnel and special hoist systems may be necessary to prevent injury to staff. ${ }^{5}$ Morbidly obese patients are at an increased risk of positioning-related peripheral neuropathy. ${ }^{37}$ Standard spinal frames and devices (such as Wilson frames and Gillespie pillows) have little flexibility to accommodate patients of large dimensions and may exacerbate, rather than alleviate, problems with pressure-area care, resulting in greater risk of skin breakdown. As of yet, there are no specialized bariatric spinal frames or operating tables in widespread use, which is clearly an area of need.

\section{Surgical Approaches and Techniques}

Due to the poor x-ray penetrance in the morbidly obese patient, image quality from an intraoperative 2D or 3D fluoroscopic C-arm may be excessively degraded for identifying the spinal levels or guiding instrument positioning. Intraoperative 3D fluoroscopic O-arm devices and the intraoperative fixed or mobile CT scanner may not always have wide enough apertures to accommodate and image some morbidly obese patients. As encountered in Case 5, the C-arm device did not adequately image the cervical spine. It is standard practice to place a spinal needle at an accessible level and identify the correct spinal level in relation to this level, such as in Case 4. The neurosurgeon decided that this method was not feasible in Case 5 because the spine could not be imaged below the level of the C-2 body due to her obesity, shoulder height, and shape of her neck. There was the additional difficulty in accessing the $\mathrm{C}-2$ body from the level of the skin incision to allow for level counting to commence. This difficulty could have been overcome by using intraoperative 3D fluoroscopy or CT, which might assist in guiding and confirming instrument placement.

Due to the excessive depth of the subcutaneous adipose tissue in the obese, longer incisions may be necessary for adequate exposure. ${ }^{45}$ Satisfactory retraction may also be rendered difficult by the deep subcutaneous tissue layer. ${ }^{42,45}$ Bariatric instruments or a fixed retractor system such as Scoville, TrimLine (Medtronic), or Koros retractors may ameliorate this issue. ${ }^{23,45}$ However, such equipment may not be readily available, and many spinal instrumentation manufacturers do not currently provide longer instruments for use in bariatric patients. More extensive and invasive approaches may be required, such as the sternotomy in Case 4, to reach the surgical objective.

Technical challenges and risks of morbidity also apply with bone autograft harvesting, such as the iliac crest strut graft used in Case 2. To avoid donor site morbidity, grafting with allograft bone, bone substitute, or the insertion of synthetic cages are alternatives, but are subject to their availability and the consideration of a lower fusion rate.

\section{Blood Loss}

Venous epidural bleeding can be greater due to increased intraabdominal and intrathoracic pressures in the obese patient with impaired venous return to the heart, particularly in the prone position. Use of the Cell Saver (Haemonetics Corp.) may maintain oxygen carrying capacity and reduce transfusion requirements.

\section{Postoperative Wound Care}

It has been shown that there is a greater incidence of wound breakdown and surgical site infection in the mor-

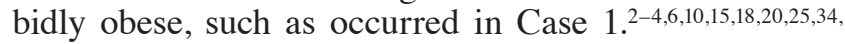
$35,43,48$ In addition to surgical site infections, the morbidly obese are at greater risk of pressure sores., ${ }^{1,27}$ Substantial padding intraoperatively and postoperatively, in addition to frequent inspection of the skin at pressure points and the use of oscillating air mattresses, may reduce pressure areas. $^{13}$ 


\section{Venous Thromboembolism}

The incidence of venous thromboembolism is greater in obese patients because of venous stasis due to raised intraabdominal pressure and relative immobility, and to a hypercoagulable state.,13,36,39 Perioperative pneumatic calf compressors may reduce the risk of postoperative venous thromboembolism in this population. However, it may be difficult to acquire large enough compression devices for some morbidly obese patients. ${ }^{1}$ Ultrasonography diagnosis may be more difficult due to the degradation of images associated with morbid obesity.

The incidence of deep venous thrombosis and pulmonary embolism is reduced with the use of prophylactic LMWH. ${ }^{21}$ However, initiation of LMWH prophylaxis is often delayed because of injury-related intracranial, intraspinal, or other bleeding, as well as deferment associated with planned operative intervention. On a weight-adjusted basis, morbidly obese patients should receive the same dose of LMWH, although there is evidence that twicedaily dosing of $1 \mathrm{mg} / \mathrm{kg}$ is safer for patients with a BMI greater than 35 or a weight greater than $150 \mathrm{~kg}(330 \mathrm{lbs}){ }^{21}$

\section{Orthoses}

At the initial scene of a trauma, paramedics may not be able to fit a morbidly obese patient with a cervical collar, necessitating the use of suboptimal alternatives for immobilization, such as sandbags and head taping to the spinal board. Once the patients are transferred to a trauma center, there may be difficulty obtaining appropriately sized orthoses, including halo-thoracic braces, collars, and thoracolumbar braces. The use of custommade braces and orthoses, such as in Cases 1 and 4, is dependent on an experienced orthotics department. As an alternative, a cervical collar could be applied, opened as wide as possible, secured with an overlapping Velcro strap, and reinforced with casting material, which is then cut and taped over for easy removal.

\section{Postoperative Pulmonary Care}

Early fixation and mobilization of morbidly obese patients with spinal injuries reduces the incidence of respiratory insufficiency and pneumonia. ${ }^{31}$ Speech pathologists should identify the morbidly obese patients with cervical spine injuries at risk for aspiration.

\section{Conclusions}

Spine surgeons and trauma specialists should be cognizant of the significant logistical, medical, and societal challenges posed by morbidly obese patients with spine trauma, who are increasing in number. With greater awareness and with improvements in medical techniques and technology, hospitals can develop management pathways and guidelines to reduce adverse neurological and overall outcomes for morbidly obese patients.

\section{Disclosure}

The authors report no conflict of interest concerning the materials or methods used in this study or the findings specified in this paper.

Author contributions to the study and manuscript preparation include the following. Conception and design: JV Rosenfeld, Limb, Chan. Acquisition of data: H Rosenfeld, Limb, Bradley. Analysis and interpretation of data: Limb, JV Rosenfeld, Chan. Drafting the article: H Rosenfeld, Limb, Fitzgerald. Critically revising the article: all authors. Reviewed submitted version of manuscript: all authors. Approved the final version of the manuscript on behalf of all authors: JV Rosenfeld.

\section{References}

1. Adams JP, Murphy PG: Obesity in anaesthesia and intensive care. Br J Anaesth 85:91-108, 2000

2. Anaya DA, Dellinger EP: The obese surgical patient: a susceptible host for infection. Surg Infect (Larchmt) 7:473-480, 2006

3. Andreshak TG, An HS, Hall J, Stein B: Lumbar spine surgery in the obese patient. J Spinal Disord 10:376-379, 1997

4. Bamgbade OA, Rutter TW, Nafiu OO, Dorje P: Postoperative complications in obese and nonobese patients. World J Surg 31:556-561, 2007

5. Bein B, Scholz J: Anaesthesia for adults undergoing non-bariatric surgery. Best Pract Res Clin Anaesthesiol 25:37-51, 2011

6. Bochicchio GV, Joshi M, Bochicchio K, Nehman S, Tracy JK, Scalea TM: Impact of obesity in the critically ill trauma patient: a prospective study. J Am Coll Surg 203:533-538, 2006

7. Byrnes MC, McDaniel MD, Moore MB, Helmer SD, Smith RS: The effect of obesity on outcomes among injured patients. J Trauma 58:232-237, 2005

8. Cameron AJ, Welborn TA, Zimmet PZ, Dunstan DW, Owen N, Salmon J, et al: Overweight and obesity in Australia: the 1999-2000 Australian Diabetes, Obesity and Lifestyle Study (AusDiab). Med J Aust 178:427-432, 2003

9. Candiotti K, Sharma S, Shankar R: Obesity, obstructive sleep apnoea, and diabetes mellitus: anaesthetic implications. Br J Anaesth 103 (Suppl 1):i23-i30, 2009

10. Cheadle WG: Risk factors for surgical site infection. Surg Infect (Larchmt) 7 (Suppl 1):S7-S11, 2006

11. Christmas AB, Reynolds J, Wilson AK, Franklin GA, Miller FB, Richardson JD, et al: Morbid obesity impacts mortality in blunt trauma. Am Surg 73:1122-1125, 2007

12. de Bucourt M, Streitparth F, Wonneberger U, Rump J, Teichgräber U: Obese patients in an open MRI at 1.0 Tesla: image quality, diagnostic impact and feasibility. Eur Radiol 21: 1004-1015, 2011

13. DeMaria EJ, Carmody BJ: Perioperative management of special populations: obesity. Surg Clin North Am 85:1283-1289, xii, 2005

14. Diaz JJ Jr, Norris PR, Collier BR, Berkes MB, Ozdas A, May $\mathrm{AK}$, et al: Morbid obesity is not a risk factor for mortality in critically ill trauma patients. J Trauma 66:226-231, 2009

15. Dindo D, Muller MK, Weber M, Clavien PA: Obesity in general elective surgery. Lancet 361:2032-2035, 2003

16. Duchesne JC, Schmieg RE Jr, Simmons JD, Islam T, McGinness CL, McSwain NE Jr: Impact of obesity in damage control laparotomy patients. J Trauma 67:108-114, 2009

17. Evans DC, Stawicki SP, Davido HT, Eiferman D: Obesity in trauma patients: correlations of body mass index with outcomes, injury patterns, and complications. Am Surg 77:10031008,2011

18. Falagas ME, Kompoti M: Obesity and infection. Lancet Infect Dis 6:438-446, 2006

19. Finucane MM, Stevens GA, Cowan MJ, Danaei G, Lin JK, Paciorek CJ, et al: National, regional, and global trends in body-mass index since 1980: systematic analysis of health examination surveys and epidemiological studies with 960 country-years and 9.1 million participants. Lancet 377:557567,2011

20. Fleischmann E, Kurz A, Niedermayr M, Schebesta K, Kimberger O, Sessler DI, et al: Tissue oxygenation in obese and non-obese patients during laparoscopy. Obes Surg 15:813819,2005 
21. Freeman A, Horner T, Pendleton RC, Rondina MT: Prospective comparison of three enoxaparin dosing regimens to achieve target anti-factor Xa levels in hospitalized, medically ill patients with extreme obesity. Am J Hematol 87:740-743, 2012

22. Grant P, Newcombe M: Emergency management of the morbidly obese. Emerg Med Australas 16:309-317, 2004

23. Greenleaf RM, Altman DT: Evaluation and treatment of spinal injuries in the obese patient. Orthop Clin North Am 42: 85-93, vi-vii, 2011

24. Gregg SC, Murthi SB, Sisley AC, Stein DM, Scalea TM: U1trasound-guided peripheral intravenous access in the intensive care unit. J Crit Care 25:514-519, 2010

25. Harrop JS, Styliaras JC, Ooi YC, Radcliff KE, Vaccaro AR, Wu C: Contributing factors to surgical site infections. J Am Acad Orthop Surg 20:94-101, 2012

26. Hoffmann M, Lefering R, Gruber-Rathmann M, Rueger JM, Lehmann W: The impact of BMI on polytrauma outcome. Injury 43:184-188, 2012

27. Jupiter JB, Ring D, Rosen H: The complications and difficulties of management of nonunion in the severely obese. J Orthop Trauma 9:363-370, 1995

28. Juvin P, Blarel A, Bruno F, Desmonts JM: Is peripheral line placement more difficult in obese than in lean patients? Anesth Analg 96:1218, 2003

29. Juvin P, Lavaut E, Dupont H, Lefevre P, Demetriou M, Dumoulin JL, et al: Difficult tracheal intubation is more common in obese than in lean patients. Anesth Analg 97:595-600, 2003

30. Kristensen MS: Airway management and morbid obesity. Eur J Anaesthesiol 27:923-927, 2010

31. McHenry TP, Mirza SK, Wang J, Wade CE, O'Keefe GE, Dailey AT, et al: Risk factors for respiratory failure following operative stabilization of thoracic and lumbar spine fractures. J Bone Joint Surg Am 88:997-1005, 2006

32. Meroz Y, Gozal Y: Management of the obese trauma patient. Anesthesiol Clin 25:91-98, ix, 2007

33. Neville AL, Brown CV, Weng J, Demetriades D, Velmahos GC: Obesity is an independent risk factor of mortality in severely injured blunt trauma patients. Arch Surg 139:983-987, 2004

34. Newell MA, Bard MR, Goettler CE, Toschlog EA, Schenarts PJ, Sagraves SG, et al: Body mass index and outcomes in critically injured blunt trauma patients: weighing the impact. J Am Coll Surg 204:1056-1064, 2007

35. Olsen MA, Nepple JJ, Riew KD, Lenke LG, Bridwell KH, Mayfield J, et al: Risk factors for surgical site infection following orthopaedic spinal operations. J Bone Joint Surg Am 90:62-69, 2008

36. Parkin L, Sweetland S, Balkwill A, Green J, Reeves G, Beral $\mathrm{V}$ : Body mass index, surgery, and risk of venous thromboembolism in middle-aged women: a cohort study. Circulation 125:1897-1904, 2012
37. Patel N, Bagan B, Vadera S, Maltenfort MG, Deutsch H, Vaccaro AR, et al: Obesity and spine surgery: relation to perioperative complications. J Neurosurg Spine 6:291-297, 2007

38. Pelosi P, Gregoretti C: Perioperative management of obese patients. Best Pract Res Clin Anaesthesiol 24:211-225, 2010

39. Platzer P, Thalhammer G, Jaindl M, Obradovic A, Benesch T, Vecsei V, et al: Thromboembolic complications after spinal surgery in trauma patients. Acta Orthop 77:755-760, 2006

40. Roth J, Qiang X, Marbán SL, Redelt H, Lowell BC: The obesity pandemic: where have we been and where are we going? Obes Res 12 (Suppl 2):88S-101S, 2004

41. Rothschild PA, Domesek JM, Eastham ME, Kaufman L: MR imaging of excessively obese patients: the use of an open permanent magnet. Magn Reson Imaging 9:151-154, 1991

42. Sarr MG, Felty CL, Hilmer DM, Urban DL, O'Connor G, Hall BA, et al: Technical and practical considerations involved in operations on patients weighing more than $270 \mathrm{~kg}$. Arch Surg 130:102-105, 1995

43. Serrano PE, Khuder SA, Fath JJ: Obesity as a risk factor for nosocomial infections in trauma patients. J Am Coll Surg 211:61-67, 2010

44. Swinburn BA, Sacks G, Hall KD, McPherson K, Finegood DT, Moodie ML, et al: The global obesity pandemic: shaped by global drivers and local environments. Lancet 378:804814, 2011

45. Telfeian AE, Reiter GT, Durham SR, Marcotte P: Spine surgery in morbidly obese patients. J Neurosurg (1 Suppl) 97:20-24, 2002

46. Uppot RN: Impact of obesity on radiology. Radiol Clin North Am 45:231-246, 2007

47. Uppot RN, Sahani DV, Hahn PF, Gervais D, Mueller PR: Impact of obesity on medical imaging and image-guided intervention. AJR Am J Roentgenol 188:433-440, 2007

48. Wimmer C, Gluch H, Franzreb M, Ogon M: Predisposing factors for infection in spine surgery: a survey of 850 spinal procedures. J Spinal Disord 11:124-128, 1998

49. World Health Organization: BMI Classification. Geneva: World Health Organization, 2012 (http://apps.who.int/bmi/ index.jsp?introPage=intro_3.html) [Accessed April 10, 2013]

50. Wutzler S, Maegele M, Marzi I, Spanholtz T, Wafaisade A, Lefering R: Association of preexisting medical conditions with in-hospital mortality in multiple-trauma patients. J Am Coll Surg 209:75-81, 2009

Manuscript submitted September 25, 2012.

Accepted April 8, 2013.

Please include this information when citing this paper: published online May 21, 2013; DOI: 10.3171/2013.4.SPINE12876.

Address correspondence to: Jeffrey V. Rosenfeld, M.D., M.S., Department of Surgery, Level 6, The Alfred Centre, 99 Commercial Road, Melbourne, Australia 3004. email: j.rosenfeld@alfred.org.au. 